\title{
Is Laparoscopic Cholecystectomy Safe in Gombe, Nigeria?
}

\author{
Emmanuel L Mba ${ }^{1}$, Nuhu M Mshelia², Sunday K Obiano ${ }^{3}$
}

\begin{abstract}
Aim: This study compares the outcome of laparoscopic cholecystectomy (LC) and open cholecystectomy (OC) in terms of the duration of surgery, the length of hospital stay, the postoperative analgesia, and the postoperative complications, in order to determine the safety of LC in our center. Materials and methods: This is a retrospective study. All patients who had cholecystectomy in Federal Teaching Hospital, Gombe, Nigeria, between January 2012 and December 2016 were studied. Their relevant data were obtained from the records and analyzed using SPSS version 20.0. $t$ test was employed and a $p$ value of $<0.05$ was considered to be significant.

Results: A total of 26 patients had cholecystectomy during the period-four of them were excluded, three had additional procedures while one had incomplete records. The female-to-male ratio was 1.2:1 and the mean age was 39 years. The indications for surgery were symptomatic gallstones in all patients except in one, which was for an acalculous cholecystitis. Fifteen (68\%) patients had LC while seven (32\%) had OC. The mean age for $L C$ was 38 years and for OC it was 41 years. The mean duration of procedure was $73( \pm 17.4)$ minutes for $L C$ and $92( \pm 28.0)$ minutes for OC. This was not statistically significant ( $p$ value $=0.066$ ). The mean length of hospital stay for LC was $5.8( \pm 5.5)$ days and $10( \pm 8.5)$ days for $O C$, and was equally not statistically significant ( $p$ value $=0.433$ ). There was no difference in postoperative analgesia, no surgical site infection or mortality recorded.

Conclusion: LC is very safe and has a good outcome in our environment despite our challenges.

Clinical significance: LC is still nascent and has not been studied in our environment. This study affirms the safety of this procedure, but fails to establish its superiority over OC.

Keywords: Cholecystectomy, Gombe, Laparoscopic, Nigeria, Open.

World Journal of Laparoscopic Surgery (2018): 10.5005/jp-journals-10033-1355
\end{abstract}

\section{INTRODUCTION}

Cholecystectomy is the surgical removal of a diseased gallbladder and may be either LC or OC. LC is the gold standard and has revolutionized the treatment of gallbladder, since its introduction in 1987 by Mouret Philippe. ${ }^{1,2}$ The advantages include reduced postoperative pain, rapid recovery, shorter hospital stay, early return to work, and better cosmetic outcome. ${ }^{2,3}$ In the developed countries, LC is the procedure mostly performed and OC is often performed as a result of conversion from LC. This is not the case in the developing countries, where $O C$ is mostly performed. ${ }^{4,5}$ In Nigeria, LC is still nascent and not widely available. High cost, unstable power supply, lack of awareness, and inadequate expertise are some of the reasons. Despite the drawbacks, many centers in Nigeria have good outcome. ${ }^{6-10}$ Laparoscopic surgeries in our $^{-1}$ center were initially done by the Department of Obstetric and Gynaecology for diagnostic purposes, until 2012, when therapeutic procedures were started with the assistance of a visiting general surgeon. We now have a trained general surgeon who does most of the laparoscopic procedures.

The aim of this study is to compare the outcome of LC and OC in terms of the duration of surgery, the length of hospital stay, the postoperative analgesia, and the postoperative complications, in order to determine the safety of LC in our center.

\section{Materials and Methods}

This is a retrospective study. All patients who had cholecystectomy in Federal Teaching Hospital, Gombe, Nigeria, between January 2012 and December 2016 were studied. Their relevant data were obtained from the records and analyzed using SPSS version 20.0. $t$ test was employed and a $p$ value of $<0.05$ was considered to be significant.

\footnotetext{
${ }^{1-3}$ Department of Surgery, Federal Teaching Hospital, Gombe, Nigeria Corresponding Author: Emmanuel L Mba, Department of Surgery, Federal Teaching Hospital, Gombe, Nigeria, Phone: +2348063924442 , e-mail:dremmamba@yahoo.com

How to cite this article: Mba EL, Mshelia NM, et al. Is Laparoscopic Cholecystectomy Safe in Gombe, Nigeria? World J Lap Surg 2018;11(3):132-134.
}

Source of support: Nil

Conflict of interest: None

LC was done under general anesthesia using a four-port system. Pneumoperitoneum was achieved with $\mathrm{CO}_{2}$. A $10 \mathrm{~mm}$ umbilical port for the camera was inserted and a $10 \mathrm{~mm}$ port at the epigastrium under direct vision. The other two $5 \mathrm{~mm}$ ports at the right hypochondrial and iliac fossae were also inserted under direct vision. Clips were applied on the cystic duct and artery after dissection around the Calot's triangle. The gallbladder was retrieved via the epigastric port and sometimes, the bile was suctioned or the incision increased to help deliver the gallbladder. The OC was done conventionally under general anesthesia via the right subcostal incision. All patients received paracetamol and pentazocine injections postoperatively.

\section{RESULTS}

A total of 26 patients had cholecystectomy during the study period. Four of them were excluded, three had additional procedures while one had incomplete records. Out of the 22 patients, $12(54.5 \%)$ were females and 10 (45.5\%) were males, with a female-to-male ratio of 1.2:1. The age range was $18-70$ years and the mean age

() The Author(s). 2018 Open Access This article is distributed under the terms of the Creative Commons Attribution 4.0 International License (https://creativecommons. org/licenses/by-nc/4.0/), which permits unrestricted use, distribution, and non-commercial reproduction in any medium, provided you give appropriate credit to the original author(s) and the source, provide a link to the Creative Commons license, and indicate if changes were made. The Creative Commons Public Domain Dedication waiver (http://creativecommons.org/publicdomain/zero/1.0/) applies to the data made available in this article, unless otherwise stated. 


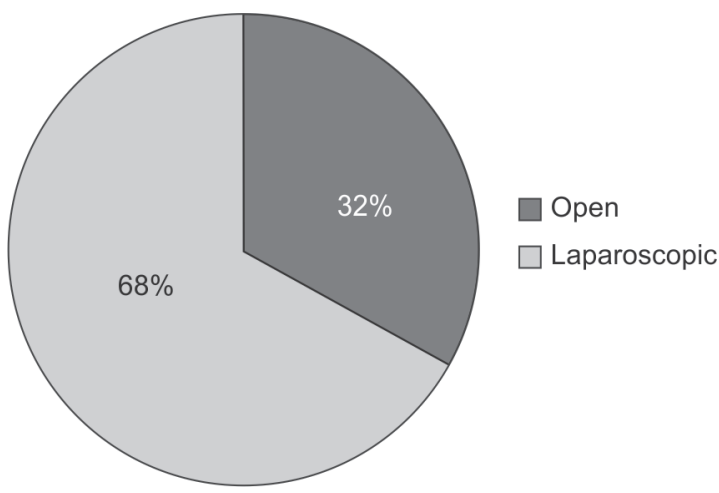

Fig. 1: Pie chart shows $68 \%$ of $L C$ and $32 \%$ of OC

Table 1: Comparison of laparoscopic and open cholecystectomy in Gombe, Nigeria

\begin{tabular}{|c|c|c|}
\hline & Laparoscopic & Open \\
\hline Males & 7 & 3 \\
\hline Females & 8 & 4 \\
\hline Total & $15(68 \%)$ & $7(32 \%)$ \\
\hline Age in years (mean) & $18-53(38)$ & $30-70(41)$ \\
\hline $\begin{array}{l}\text { Duration of surgery } \\
\text { (minutes) }\end{array}$ & 75.3 & 92.1 \\
\hline Hospital stay (days) & 5.8 & 11 \\
\hline Postoperative analgesia & $\begin{array}{l}\text { Pentazocine } \\
\text { and PCM }\end{array}$ & $\begin{array}{l}\text { Pentazocine and } \\
\text { PCM }\end{array}$ \\
\hline $\begin{array}{l}\text { Postoperative } \\
\text { complication }\end{array}$ & Paralytic ileus & $\begin{array}{l}\text { Postoperative } \\
\text { adhesion }\end{array}$ \\
\hline
\end{tabular}

was 39 years. The indications were for symptomatic gallstones in all patients except in one which was for an acalculous cholecystitis.

The LC were 15 (68\%), of which seven were males and eight were females, while the age range was $18-53$ years (mean $=38$ years). The OC were seven (32\%) with three males and four females, and the age was between 30 and 70 years (mean $=41$ years) (Fig. 1). The duration of the procedure for LC was 45-105 minutes with a mean of $73( \pm 17.4)$ minutes, while for OC it was $60-135$ minutes and the mean was $92( \pm 28.0)$ minutes, with a $p$ value of 0.066 , which was not statistically significant. The length of hospital stay was 3-14 days with a mean of $5.8( \pm 5.5)$ days for LC, while OC had a hospital stay of 4-23 days and the mean was 10 ( \pm 8.5 ) days. The $p$ value was 0.433 and was equally not statistically significant (Table 1 ).

One patient in the LC group developed paralytic ileus postoperatively while one in the OC group developed postoperative adhesion. There was no conversion from LC to OC, no difference in postoperative analgesia, no surgical site infection noted, and no mortality recorded.

\section{Discussion}

The low volume of patients can be explained by the rarity of these cases in our environment. ${ }^{11}$ Although the trend is changing, especially with the introduction of LC. ${ }^{12,13}$

The female-to-male ratio was 1.2:1 as against 5:1 seen in other studies. ${ }^{11,12}$ This was surprising since gallstones were more common in females than in males. It could be that less females presented due to may be religious and/or cultural reasons. The mean age was 39 years as seen also in a study by Asuquo et al. ${ }^{11}$ Symptomatic gallstones were the indication in all patients except in one which was for an acalculous cholecystitis. The same was also seen in a report by Afuwape et al. ${ }^{9}$ The duration of LC was $73( \pm 17.4)$ minutes while OC was $92( \pm 28.0)$ minutes and was not statistically significant. The duration of LC was longer than 47 minutes recorded by Salam et al. ${ }^{14}$ The prolonged duration was due to the learning curve and some technical issues, such as instrument malfunction and unstable power supply. However, it is comparable to other studies. ${ }^{7,10}$ The mean length of hospital stay for LC was $5.8( \pm 5.5)$ days while for OC it was $10( \pm 8.5)$ days. This was longer than those seen in other studies ${ }^{7,10,15}$ but shorter than 7.5 days seen in Afuwape et al. ${ }^{9}$ Some centers perform LC as a day-case. ${ }^{6,16}$ Being a new procedure, we were cautious to avoid rejection, hence the long duration of hospital stay.

All patients had paracetamol and pentazocine injections postoperatively and so there was no difference in the postoperative analgesia. There was no conversion to open in our study which was in keeping with a study by Ekwunife et al. ${ }^{6}$ However, the conversion rate in other studies ranges from 1.9 to $9.1 \% .^{7,17}$ There was no mortality as also seen in a report by Misauno. ${ }^{7}$ The challenges we encountered, apart from those earlier mentioned, include lack of appropriate instruments, inadequate laparoscopic towers, and inadequate supporting staff. The limitations of this study include poor record keeping and low volume of patients.

\section{Conclusion}

This study did not establish the superiority of LC over OC, may be because it is still a new procedure in our environment. However, LC is very safe and has a good outcome in our environment, despite our challenges. Patient selection may have accounted for the favorable results. More surgeons should be trained in this aspect and we will recommend that it be integrated in the residency program.

\section{Clinical Significance}

LC is still nascent and has not been studied in our environment. This study affirms the safety of this procedure, but fails to establish its superiority over OC.

\section{ACKnowledgment}

We wish to acknowledge Prof. Philip Mshelbwala for his immense contribution.

\section{References}

1. Taki-Eldin A, Badawy AE. Outcome of laparoscopic cholecystectomy in patients with gallstone disease at a secondary level care hospital. Arq Bras Cir Dig 2018;31(1):e1347. DOI: 10.1590/0102$672020180001 \mathrm{e} 1347$.

2. Polychronidis $A$, Laftsidis $P$, et al. Twenty years of laparoscopic cholecystectomy: Philippe Mouret-March 17, 1987. JSLS 2008;12(1):109-111.

3. Lombardo S, Rosenberg JS, et al. Cost and outcomes of open vs laparoscopic cholecystectomy in Mongolia. J Surg Res 2018;229: 186-191. DOI: 10.1016/j.jss.2018.03.036.

4. Hussain A, Mahmood HK, et al. Laparoscopic cholecystectomy can be safely performed in a resource-limited setting: the first 49 laparoscopic cholecystectomies in Yemen. JSLS 2008;12(1):71-76.

5. Sanogo ZZ, Sangare D, et al. Laparoscopic cholecystectomy. The first 30 cases in Bamako. Mali Med 2006;21(2):15-22.

6. Ekwunife CN, Njike Cl. Intent at day case laparoscopic cholecystectomy in owerri, Nigeria: initial experiences. Nig J Surg 2013;19(1):16-18. DOI: 10.4103/1117-6806.111501. 
7. Misauno MA. Pilot experience with Laparoscopic Cholecystectomy in Jos, Nigeria-challenges and prospects. J West Afr Coll Surg 2011;1(3):37-43.

8. Adisa AO, Lawal OO, et al. Laparoscopic cholecystectomy in lle-Ife, Nigeria. Afr J Med Med Sci 2011;40(3):221-224.

9. Afuwape 00 , Akute 00 , et al. Preliminary experience with laparoscopic cholecystectomy in a Nigerian Teaching Hospital. West Afr J Med 2012;31(2):120-123.

10. Ayandipo OO, Afuwape OO, et al. Laparoscopic cholecystectomy in Ibadan, southwest Nigeria. J West Afr Coll Surg 2013;3(2):15-26.

11. Asuquo ME, Umoh MS, et al. Cholecystectomy: indications at University of Calabar Teaching Hospital, Calabar, Nigeria. Ann Afr Med 2008(1);7:35-37. DOI: 10.4103/1596-3519.55686.

12. Rahman GA. Cholelithiasis and cholecystitis: Changing prevalence in an African community. J Natl Med Assoc 2005;97(11):1534-1538.
13. Adisa AO, Lawal OO, et al. Trend over time for cholecystectomy following the introduction of laparoscopy in a Nigerian Tertiary Hospital. Niger J Surg 2017;23(2):102-105. DOI: 10.4103/njs.NJS_56_16.

14. Salam IM, Own A, et al. Laparoscopic Cholescystectomy. In The Academy Medical centre, Khartoum, Sudan. East Afr Med J 2005;82(1):10-13. DOI: 10.4314/eamj.v82i1.9287.

15. Gyedu A, Bingener J, et al. Starting a Laparoscopic Surgery Programme in the Second Largest Teaching Hospital in Ghana. East Afr Med J 2014;91(4):133-137.

16. Seleem MI, Gerges SS, et al. Laparoscopic cholecystectomy as a day surgery procedure: is it safe?-An Egyptian Experience. Saudi J Gastroenterol 2011;17(4):277-279. DOI: 10.4103/1319-3767.82584.

17. Clegg-Lamptey JN, Amponsah G. Laparoscopic cholecystectomy at the Korle Bu Teaching Hospital, Accra, Ghana: an initial report. West Afr J Med 2010;29(2):113-116. 